\title{
The parasitoid community of Andricus quercuscalifornicus and its association with gall size, phenology, and location
}

\author{
Maxwell B. Joseph • Melanie Gentles • Ian S. Pearse
}

Received: 1 June 2010/Accepted: 18 November 2010/Published online: 1 December 2010

(C) The Author(s) 2010. This article is published with open access at Springerlink.com

\begin{abstract}
Plant galls are preyed upon by a diverse group of parasitoids and inquilines, which utilize the gall, often at the cost of the gall inducer. This community of insects has been poorly described for most cynipid-induced galls on oaks in North America, despite the diversity of these galls. This study describes the natural history of a common oak apple gall (Andricus quercuscalifornicus [Cynipidae]) and its parasitoid and inquiline community. We surveyed the abundance and phenology of members of the insect community emerging from 1234 oak apple galls collected in California's Central Valley and found that composition of the insect community varied with galls of different size, phenology, and location. The gall maker, A. quercuscalifornicus, most often reached maturity in larger galls that developed later in the season. The parasitoid Torymus californicus [Torymidae] was associated with smaller galls, and galls that developed late in the summer. The most common parasitoid, Baryscapus gigas [Eulophidae], was more abundant in galls that developed late in the summer, though the percentage of galls attacked remained constant throughout the season. A lepidopteran inquiline of the gall (Cydia latiferreana [Tortricidae] and its hymenopteran parasitoid (Bassus nucicola [Braconidae]) were associated with galls that developed early in the summer. Parasitoids and inquilines, in general, had a longer emergence period and diapause within the gall than the gall-inducer. The association of different parasite species with galls of different size and phenology suggests that different parasite species utilize galls with slight differences in traits.
\end{abstract}

Keywords Cynipidae $\cdot$ Parasitism $\cdot$ Andricus $\cdot$ Host-use $\cdot$ Oak apple gall

\author{
Abbreviations \\ MYA \\ Million years ago \\ MANCOVA Multiple analysis of covariance \\ ANCOVA Analysis of covariance \\ CCA Canonical correspondence analysis
}

M. B. Joseph · M. Gentles · I. S. Pearse $(\bowtie)$

Department of Entomology, UC Davis, One Shields Ave, Davis, CA 95616, USA

e-mail: ispearse@ucdavis.edu 


\section{Introduction}

Insects associated with plant galls have been a key model system for understanding hostparasite interactions, trophic cascades, host specificity, and other aspects of community ecology, as these multitrophic systems represent natural microcosms that are tractable for ecologists (Stone et al. 2002). Gall inducers manipulate their host plant to produce structures of varying complexity in which the gall inducer develops (Rohfritsch 1992). The most complex and species rich group of gall-inducing organisms are the cynipid gall wasps of the tribe Cynipini, which produce complex galls on various tissues of oaks. Each species of wasp usually produces a morphologically distinct gall and has a highly specific relationship with its host oak species or species group (Csoka et al. 2005; Stone et al. 2009).

Many aspects of the interaction between the wasp and its host plant are poorly understood as the mechanisms of gall induction are still largely unknown. In contrast, the abundance of the gall-inducer and its interactions with predators, parasites, and inquilines are easily observed, as galls are immobile (Stone et al. 2002). Moreover, these communities are often complex, species rich, and predominantly specific to gall wasps (though not necessarily to a particular gall wasp species). Galls frequently accumulate parasitoid individuals, which feed predominantly on the gall inducer, and inquilines, which feed on the gall itself_-an act that may harm the gall inducer. Likewise, the parasitoids or inquilines of the gall may be attacked by yet another trophic level of hyperparasitoids. Fossils from Pleistocene deposits depict multiple levels of trophic interactions in galls, and 90 MYA fossils of the gall wasps themselves reveal these interactions to be ancient (Liu et al. 2007; Stone et al. 2008).

Parasitoid and inquiline communities have been described for many Palearctic gallinducing cynipid wasps (Bailey et al. 2009; Schönrogge et al. 1996; Stone et al. 1995). However, the parasitoid communities of most Nearctic cynipid species are not as well described-even though North America is a center of diversity for cynipid wasps and likely for their parasitoids (Dreger-Jauffret and Shorthouse 1992). Recent studies have begun to identify the functional and evolutionary mechanisms by which parasitoids associate with specific gall inducers (Askew 1980; Bailey et al. 2009). Similarly, many of the taxonomic and phylogenetic challenges within the Cynipidae are being resolved (Csoka et al. 2005; Ronquist and Liljeblad 2001). However, the natural history of most gall inducers and their parasitoids is not well described (Stone et al. 2002).

Gall traits may in part drive associations with particular parasitoids. Several hypotheses have been proposed to explain what drives the evolution of particular gall traits (Hayward and Stone 2005). Galls provide their inducer with a consistent food source, a predictable abiotic environment, and a refuge from potential enemies. Each of these functions are proposed as drivers of gall morphology in the "nutrition hypothesis", "microclimate hypothesis", and "natural enemy hypothesis" respectively. Experimental manipulations of abiotic conditions of gall wasps removed from their gall show wasp larval survival is optimized to the internal conditions of the gall (Miller et al. 2009). While predictable resources and abiotic conditions are obvious benefits of gall-induction (and could perhaps have driven the repeated evolution of gall-induction in diverse taxa), they are unlikely to contribute to the high morphological diversity of the exterior of galls, as all galls provide their inducer to some degree with resources and shelter from desiccation regardless of the exterior modifications to the gall.

Escape from natural enemies presents a more compelling raison d'etre for particular gall morphologies as different gall traits may provide the gall-inducer refuge from its various parasites or predators. Weis et al. $(1992,1985,1994)$ showed that the size of 
Eurosta-induced galls on Solidago was under opposing selection pressures by parasitoids that attacked small galls and woodpeckers that preferentially attacked large galls. Bailey et al. (2009) compared the parasitoid communities and rates of parasitoid attack in 40 species of Eastern European gall wasps and found both the composition of the parasitoid community and parasitoid attack rate could be described as a function of gall traitssuch as hairiness, gall size, and gall toughness - and gall phenology. Seasonal variation in gall toughness predicted parasitoid attack of a galling sawfly (Craig et al. 1990). The size and placement of larval chambers within a gall predicted the chance of parasitism for a rose stem gall (Jones 1983).

Factors aside from gall traits may also affect the composition of parasitoid communities within the gall. Mutualisms, such as tending by ants, have been shown to decrease parasitoid abundance and affect which parasitoids could use the gall resource, though these interactions are ultimately dependent on gall traits, as the gall-inducers secrete honeydew presumably to attract ants and thereby escape parasitism (Inouye and Agrawal 2004; Washburn 1984). Askew (1980) found that host affiliation between gall inducers and plants was associated with differences in parasitoid communities in the galls, where galls on more predictable resources - such as trees - accumulated a higher diversity of parasitoids. Fernandes and Price (1992) found that habitat differences predicted the parasitism of various gall-inducing insects where, in mesic environments, galls were more often parasitized than in xeric habitats. Thus niche differentiation of parasitoids and inquilines of galls may occur among galls with different traits, phenology, ecological associations, and biogeography.

This study describes the parasitoid and inquiline insect community from Andricus quercuscalifornicus Basset, 1881 galls and assesses whether the dominant insects are associated with galls of different size, phenology, or location. Associations of parasitoids with A. quercuscalifornicus have been mentioned in the taxonomic literature; however, no comprehensive studies of parasitoids of this gall species have been conducted. We examined the abundance of 22 species of insects, which emerged from 1234 oak apple galls collected from different locations in the California Central Valley. We tracked the phenology of the gall inducer and its parasitoids and related the presence and abundance of the dominant parasitoids and inquilines to the size of the oak apple gall and the timing of gall development. An assessment of the natural history of the insects that use plant galls is required in order to understand the evolution of galls and the diversity of their parasitoids and inquilines. This study describes aspects of the natural history of an abundant gall wasp and its most common parasitoids and inquilines.

\section{Methods}

Natural history of gall wasp

The cynipid gall-inducer, A. quercuscalifornicus, induces a 5-250 cc (often apple-sized), multilocular (many wasps per gall) gall on the twigs of valley oak (Quercus lobata), a California endemic, where galls become apparent on twigs with bimodal peaks of development which occur in the late spring and mid summer (Rosenthal and Koehler 1971b). It has also been collected from closely-related oak species, $Q$. douglasii, $Q$. berberidifolia, and $Q$. garryana (Weld 1957). Gall abundances vary widely between individual trees, and extremely high gall densities of more than 50 galls per cubic meter of canopy may be supported by some trees. The range of A. quercuscalifornicus spans most of California with the extremes of southern Washington and northern Mexico (Russo 2006). 
Initially, the developing galls are green and moist throughout, but towards fall the external wall of the gall becomes harder, and the entire gall desiccates ("maturation date" in this study). Larvae grow and differentiate until fall, when fully developed adults emerge. Descriptions exist only for females of A. quercuscalifornicus, and the species is thought to be entirely parthenogenetic and univoltine (Schick 2002), although a cryptic, sexual generation cannot be ruled out, as cryptic cyclical parthenogenesis has been found in other cynipid species (Abe 2006; Rosenthal and Koehler 1971a). Similarly, oviposition has never been recorded in this species, and little is known about the exact placement of eggs on twig tissue. Andricus quercuscalifornicus has been variously divided into different subspecies by some authors (Fullaway 1911; Kinsey 1922; Russo 2006; Weld 1957), and, as yet, no molecular genetic information exists about the species. Gall abundance on twigs is correlated with shoot vigor (Rosenthal and Koehler 1971b), but other factors, such as plant genotype, likely determine inter-tree distributions of galls (Moorehead et al. 1993).

Collection of galls and rearing of insects

In summer 2007 (June 1-October 10, 2007), 1234 oak apple galls were collected from valley oaks in Davis, Woodland, and Vacaville in the Central Valley of California. Valley oaks were chosen haphazardly from natural stands, riparian areas, suburban areas, and planted groves. All galls were collected from Q. lobata, and at least 20 trees were sampled per site. Galls that had changed from an early green/red to a pale brown/white color, had begun to desiccate, and lacked emergence holes were chosen for the survey. Following collection, each individual gall was placed in a closed clear plastic cup and left outdoors at ambient temperature. Galls were checked two to three times per week from the time of collection to the end of 2007, and emerging insects were placed in clear gel capsules with a date label. Throughout 2008, galls were checked every other month, and the survey was terminated in January 2009. Galls from which nothing had emerged over the course of the study $(n=257)$ were removed from further analysis in order to minimize the effects of mortality due to experimental conditions (premature removal from the tree or subsequent fungal infection). Insects were first grouped into morphospecies. Species identifications were then acquired for most morphospecies, and voucher specimens were deposited at the UC Davis, Bohart Museum of Entomology.

Functional groups (whether the insect was a parasitoid, inquiline, or facultative gall occupant) of the most common species were determined by rearing the insects and determining where their larvae developed by repeated cross-sectioning of the galls from which they had emerged. For each of the 7 most abundant gall-occupants, galls from which only the focal insect species had emerged were chosen. The galls were then cut into $7.5 \mathrm{~mm}$ cross-sections using a band-saw, and the emergence tunnel was traced back to the larval chamber of the gall-occupant. If emergence tunnels led to the central growth chamber of A. quercuscalifornicus (which is recognizable by its connection to the plant vasculature), but no A. quercuscalifornicus had emerged from that chamber, then the insect in question was considered a parasitoid of A. quercuscalifornicus. If emergence tunnels led to the gall tissue away from an A. quercuscalifornicus chamber, then the insect was considered an inquiline. For each functional group determination, multiple galls were cross-sectioned to confirm our categorizations. This method could distinguish between parasites of the gall inducer and parasites of its inquilines, but it could not detect interactions between parasites, such as hyperparasitism.

Phenologies of the six most common gall associates were constructed using bi-monthly intervals for the intensive sampling time period (July-Dec. 2007), and at 6 month intervals 
for the less frequently sampled period (Jan.-Dec. 2008). For each of these six species, the numbers of adults emerging were summed over all galls and plotted against time.

Gall size measures and statistical analyses

Gall volume was measured using water displacement. We analyzed the association of insect species with gall traits first using only presence/absence of each insect species and using abundance information. To investigate patterns of host-use by the six most common insects emerging from oak apple galls, we used logistic regression where gall volume, maturation date (Julian date collected), and locality predicted the occurrence of a given species. To investigate the relationship between gall size or gall inducer phenology and the abundance of the six focal insect species, we ignored galls from which the species in question was absent, and used multiple analysis of covariance (MANCOVA) followed by protected analysis of covariance (ANCOVA) between gall size or gall inducer phenology and the abundance of each common insect species by locality of gall collection. When an interaction between factors was detected, we present the simple effect of either gall size or gall-inducer phenology on insect abundance. All abundance data was square-root transformed in order to meet normality assumptions. Canonical correspondence analysis (CCA) was performed in R package "vegan", and the probability of correspondence between insect community composition and gall size, phenology, and locality was assessed using a test permuting (permuted $n=100$ ) the association between the insect abundance matrix and gall traits (Oksanen et al. 2010; R Core Development Team 2008). All other statistical analyses were conducted using JMP (SAS Institute, Cary, NC).

\section{Results}

Description of $A$. quercuscalifornicus insect community

The gall-inducer, A. quercuscalifornicus, was found in the highest percentage of galls (34.85\% of galls). The three most common parasitoids of A. quercuscalifornicus were Baryscapus gigas Burk [Eulophidae], Torymus californicus Ashmead [Torymidae], and Eurytoma californica Ashmead [Eurytomidae]. Filbert moths (Cydia latiferreana Walsingham [Tortricidae]) and an associated parasitoid (Bassus nucicola Muesebeck [Braconidae]) were also among the most common insects (Table 1). The larval chambers of $C$. latiferreana and B. nucicola were separate from those of the gall inducer, though, in many cases, $C$. latiferreana galleries interrupted the plant vasculature, which leads to the gall inducer chamber. We did not find any representatives of the cynipid tribe Synergini, common inquilines of other cynipid galls, in this study. Ozognathus cornutus LeConte [Anobiidae] was the most common late stage inquiline. In its larval stage, O. cornutus fed voraciously on desiccated gall material often leaving only the outermost layer of the gall. After 2 years, many galls that had been left inside of rearing chambers contained both live larvae and adults of $O$. cornutus, suggesting that it can pass through multiple generations within the gall. Based on our observations of cross-sectioned galls, we depict the known interactions between these seven species (Fig. 1), though we could not assess interactions between different parasitoids of a given species (such as hyperparasitism). 


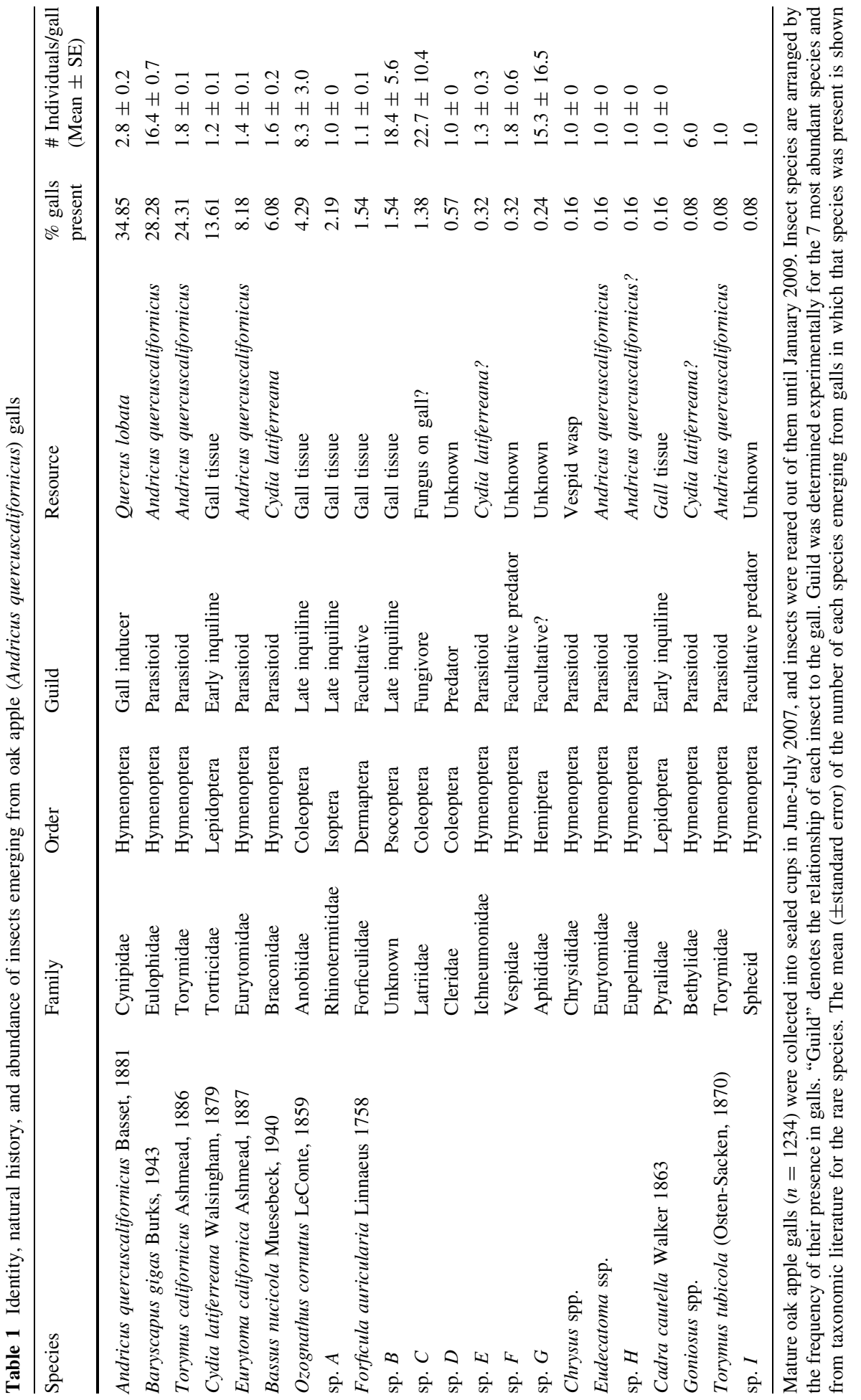




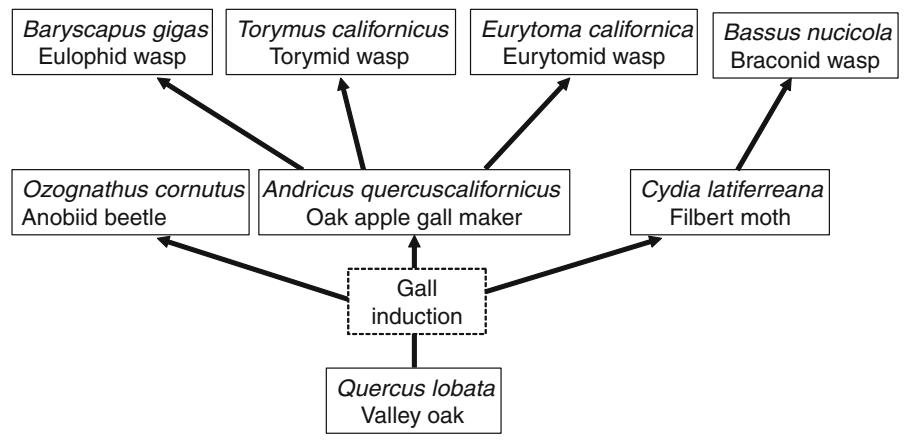

Fig. 1 Interactions between the most common insects found in oak apple galls (formed by A. quercuscalifornicus) in the Central Valley of California. Interactions arising from "Gall Induction" denote gall-inducers or inquilines (insects that feed on the gall material, not the gall-making insect). Panels are arranged by trophic level

Differences in presence and abundance of insects based on gall size and locality

Canonical correspondence analysis (CCA — an ordination technique that is robust to nonlinearity in species associations across environmental gradients) showed that insect communities within galls varied across galls of different size (CCA, permutation test, $P<0.01$ ), phenology (CCA, permutation test, $P<0.01$ ), and location (CCA, permutation test, $P<0.01)$. MANCOVA similarly revealed that the community of insects emerging from oak apple galls was associated with gall size and collection locality with linear trends (Table 2). We assessed whether individual insect species were more often present in galls based on size, phenology, or location using logistic regression (Table 2), and we assessed whether the abundance of each species of insects within the gall related to those same factors using ANCOVA (Table 3). More gall-inducers (A. quercuscalifornicus) survived to adulthood in larger galls and in galls that developed late in the summer (Table 2). Gall inducers also reached higher abundances in larger galls (Table 3). The parasitoid, T. californica, was more often present in smaller galls and in galls that emerged later in the summer. Its abundance within the galls was unrelated to the gall size, phenology, or location (Table 3). The parasitoid, B. gigas, was present more often at some localities than at others (Table 2) and reached higher abundances in galls that emerged later in the summer (Table 3). The parasitoid, E. californica, emerged more frequently from galls that developed early in the summer (Table 2), but its abundance within galls was not related to gall size, phenology, or location (Table 3). The inquiline, C. latiferreana, was associated with galls that matured late in the season at some localities, but this trend was reversed or non-existent at other localities (Table 2). The abundance of the inquiline within galls was highest from galls that developed late in the year (Table 3). Bassus nucicola, the braconid parasitoid of $C$. latiferreana, was associated with early developing galls. All insects, except for B. nucicola, varied in their frequency of emergence across localities (Table 2).

Phenology of insect community and relationship between gall inducer phenology and parasite community

Galls became desiccated and were subsequently collected throughout summer and fall 2007 with an apparent bimodal pattern of maturation (Fig. 2). The majority of gall inducers 
Table 2 The effect of oak apple gall size, gall collection locality, and gall maturation date on the presence of the dominant members of the gall insect community using nominal logistic regression

\begin{tabular}{|c|c|c|c|c|}
\hline & Gall size & Gall locality & Maturation date & Interactions \\
\hline $\begin{array}{l}\text { A. quercuscalifornicus } \\
\text { (cynipid gall-inducer) }\end{array}$ & $\begin{array}{l}(+) \chi^{2}=233.0 \\
P<0.0001\end{array}$ & $\begin{array}{l}\chi^{2}=24.5 \\
\quad P<0.0001\end{array}$ & $\begin{array}{c}(+) \chi^{2}=13.1 \\
P=0.0003\end{array}$ & NS \\
\hline $\begin{array}{l}\text { T. californicus (torymid } \\
\text { parasitoid) }\end{array}$ & $\begin{array}{c}(-) \chi^{2}=6.1 \\
P=0.01\end{array}$ & $\begin{array}{l}\chi^{2}=38.7 \\
\quad P<0.0001\end{array}$ & $\begin{array}{c}(+) \chi^{2}=10.2 \\
P=0.001\end{array}$ & NS \\
\hline $\begin{array}{l}\text { B. gigas (eulophid } \\
\text { parasitoid) }\end{array}$ & $\chi^{2}=3.6, P=0.06$ & $\begin{array}{l}\chi^{2}=95.6 \\
P<0.0001\end{array}$ & $\chi^{2}=1.2, P=0.27$ & NS \\
\hline $\begin{array}{l}\text { E. californica (eurytomid } \\
\text { parasitoid) }\end{array}$ & $\chi^{2}=0.6, P=0.45$ & $\begin{array}{l}\chi^{2}=37.4 \\
P<0.0001\end{array}$ & $\begin{array}{c}(-) \chi^{2}=7.6 \\
P=0.006\end{array}$ & NS \\
\hline \multirow[t]{4}{*}{$\begin{array}{l}\text { C. latiferreana (filbert } \\
\text { moth inquiline) }\end{array}$} & $\begin{array}{l}\text { Total: } \chi^{2}=0.1 \\
\quad P=0.71\end{array}$ & $\begin{array}{l}\chi^{2}=13.0 \\
\quad P=0.002\end{array}$ & $\begin{array}{l}\text { Total: } \chi^{2}=0.2 \\
\quad P=0.63\end{array}$ & size*locality \\
\hline & $\begin{array}{l}\text { Davis: } \chi^{2}=0.1 \\
\quad P=0.72\end{array}$ & & $\begin{array}{l}(-) \text { Davis: } \chi^{2}=27.6 \\
P<0.0001\end{array}$ & $\begin{array}{l}\chi^{2}=8.6 \\
P=0.01\end{array}$ \\
\hline & $\begin{array}{c}(-) \text { Vacaville: } \\
\chi^{2}=5.8 \\
P=0.02\end{array}$ & & $\begin{array}{l}(+) \text { Vacaville: } \\
\chi^{2}=4.6, P=0.03\end{array}$ & date*locality \\
\hline & $\begin{array}{l}\text { Woodland: } \chi^{2}=2.6 \text {, } \\
\quad P=0.10\end{array}$ & & $\begin{array}{l}\text { Woodland: } \chi^{2}=0.1 \text {, } \\
\quad P=0.71\end{array}$ & $\begin{array}{l}\chi^{2}=16.2 \\
\quad P=0.0003\end{array}$ \\
\hline \multirow[t]{4}{*}{$\begin{array}{l}\text { B. nucicola (braconid } \\
\text { parasitoid of inquiline) }\end{array}$} & $\chi^{2}=0.5, P=0.50$ & $\begin{array}{l}\chi^{2}=2.8 \\
P=0.24\end{array}$ & $\begin{array}{l}(-) \text { Total: } \chi^{2}=53.4 \\
P<0.0001\end{array}$ & date*locality \\
\hline & & & $\begin{array}{l}(-) \text { Davis: } \chi^{2}=98.2 \\
P<0.0001\end{array}$ & $\begin{array}{l}\chi^{2}=6.3 \\
\quad P=0.04\end{array}$ \\
\hline & & & $\begin{array}{c}(-) \text { Vacaville: } \\
\chi^{2}=11.2 \\
P=0.0008\end{array}$ & \\
\hline & & & $\begin{array}{c}(-) \text { Woodland: } \\
\chi^{2}=22.7 \\
P=0.0001\end{array}$ & \\
\hline
\end{tabular}

Significant interactions between terms were included and the model and are shown. When an interaction with gall locality was obnserved, the simple effects either gall size or maturation date are shown. For all complete models, 921 galls were observed. For models of simple effects within locations: Davis: $n=419$ galls, Vacaville: $n=340$ galls, Woodland: $n=162$ galls

emerged in fall 2007 with a peak emergence occurring in November 2007, while emergence was intensively monitored. In contrast, most inquilines emerged in 2008 (Fig. 2). The filbert moth (C. latiferreana) and its braconid parasitoid (B. nucicola) showed a bimodal emergence pattern, with the first peak of emergence occurring in late summer 2007 shortly after the galls were collected. E. californica was the earliest emerging parasitoid, with emergence beginning in November 2007 and continuing throughout 2008. The majority of B. gigas and T. californicus emerged in 2008, the year after gall collection. C. latiferreana and B. nucicola showed a second peak of emergence in 2008.

\section{Discussion}

A. quercuscalifornicus galls are used by a community of insects that include parasitoids, inquilines, parasitoids of inquilines, and transient occupants (Table 1). Different characteristics of galls correlate with the abundance of some of the most common insects that 


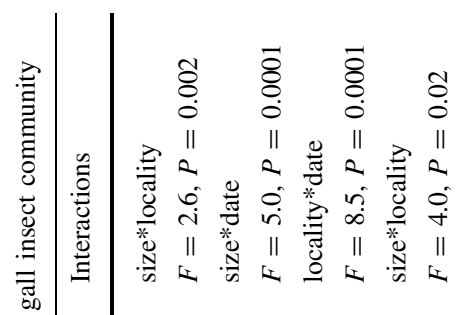
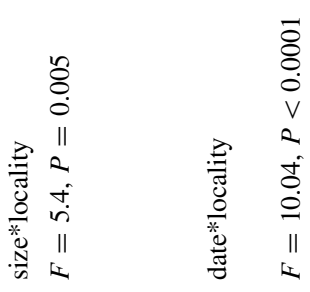

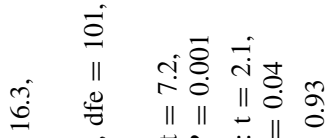
$\|$ 采

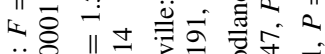

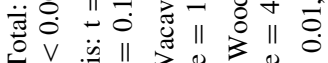

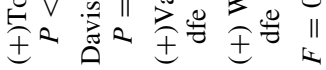

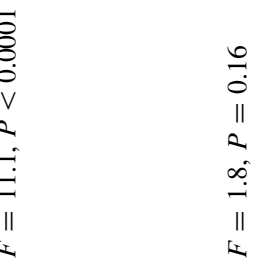

8
0
11
2
$\vdots$
$\vdots$
11
1

$\overline{8}$

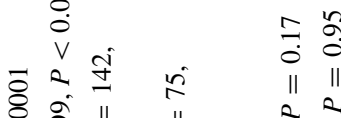

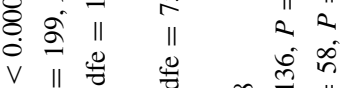

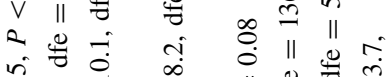

nं 0 क

처

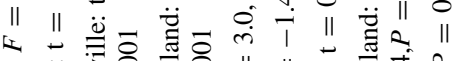

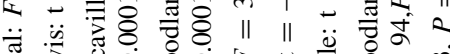

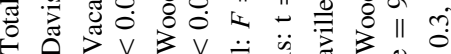

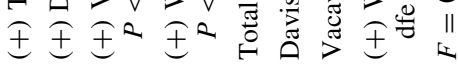

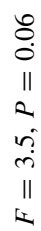

$\frac{2}{7}$

\}

m

ลิ

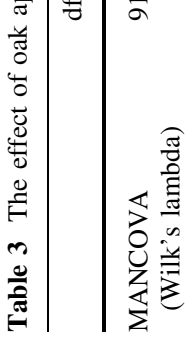

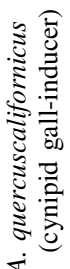

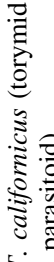

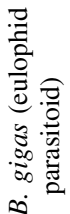




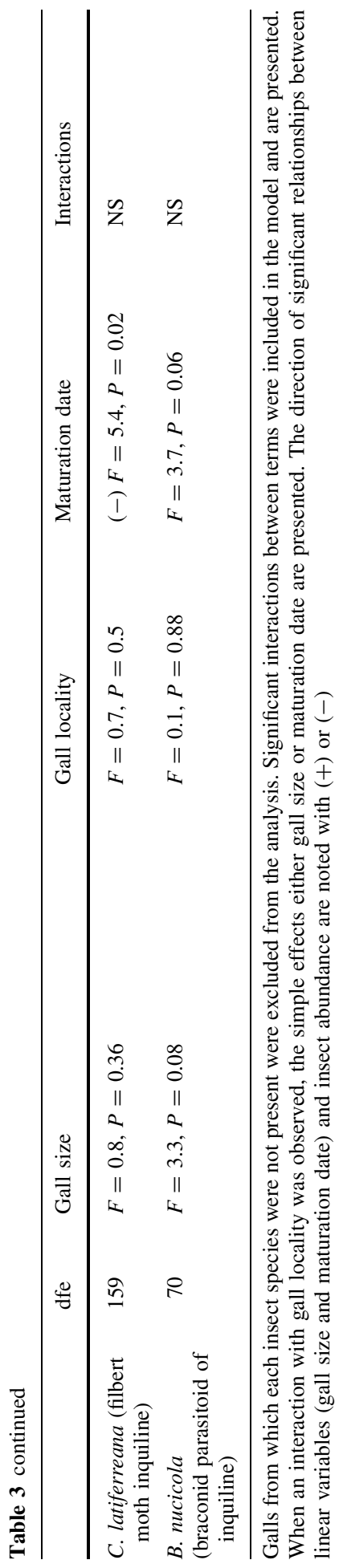




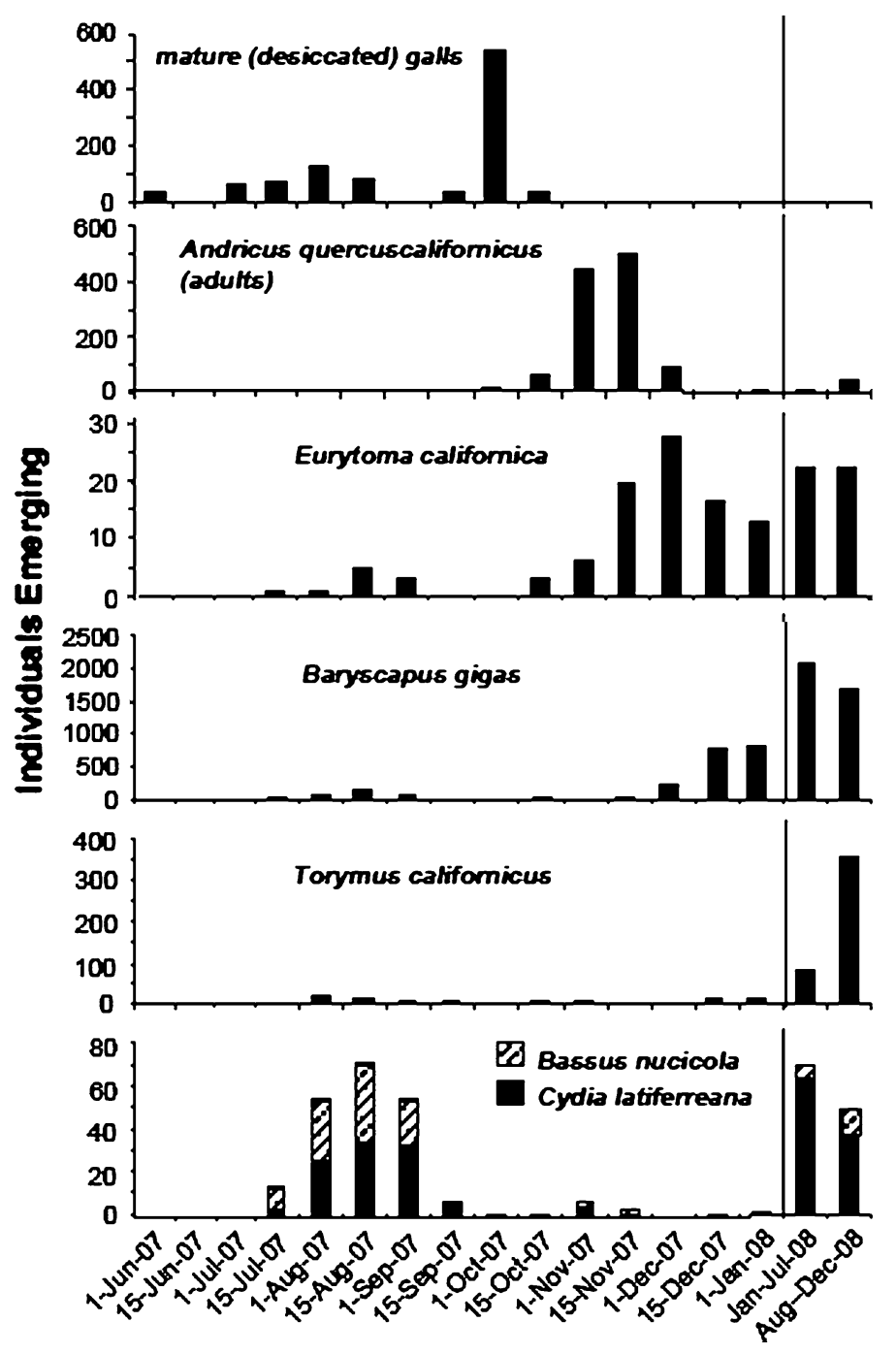

Fig. 2 Emergence time series of the gall inducer (A. quercuscalifornicus), its parasites (E. californica, B. gigas, T. californicus), and the inquiline/parasite of inquiline (C. latiferreana/B. nucicola). Mature oak apple galls were placed in sealed cups in June-July 2007. Galls were checked every 2 days from July 2007Dec 2007, and emerged insects were noted. Galls were checked less frequently from Jan 2008-Jan 2009, and data were grouped into 2 batches during this time

inhabit the galls. Different parasitoids tended to be found in galls of different sizes or from different locations (Tables 2, 3). The dominant inquiline of galls (C. latiferreana) and its major parasitoid (B. nucicola) were found more often in galls that developed early in the summer as opposed to in galls that emerged early in the summer (Tables 2,3). While each of these observations is correlative, they are consistent with a pattern of differential nicheuse of the gall by parasitoids and inquilines across gall morphology, location, and time. The subdivision of the environment into fine-scale niches is a long-standing explanation for the co-existence of ecologically similar species (Hutchinson 1959), and niche 
differentiation may account for the diversity of parasitoids associated with gall wasps. Indeed, Bailey et al. (2009) found that gall traits predicted the composition of the gall's community of parasites. But what components of parasites' natural histories drive their association with particular gall traits, phenology, or biogeography?

Why do some insects in the gall associate with galls with different sizes or phenologies? Torymids tend to be found more often in smaller galls than in larger galls (Table 2). Previous studies have shown that gall chambers that are close to the exterior wall of the gall are more susceptible to parasitism as many parasitoids are limited by the length of their ovipositor (but see Craig et al. 1990; Jones 1983; Marchosky and Craig 2004; Weis et al. 1985). If torymid parasitoids are limited in the galls that they can attack by ovipositor length (i.e. young galls, which are smaller), and attack by a torymid limits gall development by killing the gall-inducer, then torymids such as $T$. californica should emerge more frequently from smaller galls. Interestingly, T. californicus and T. tubicola were the only parasitoids with long, external ovipositors that emerged from A. quercuscalifornicus galls, and their ability to oviposit through a developing gall wall may account for which galls they emerge from. Both the inquiline, C. latiferreana, and its parasitoid, B. nucicola, were associated with galls that developed later in the season (Tables 2,3). The majority of filbert moths emerged from the galls from July through early September of the first year of gall development, though some moths (and their parasitoids) diapaused for a year (Fig. 2). In order to emerge late-summer, the inquiline and its parasitoid would need to develop in the early-developing oak apple galls (Fig. 2). As the oak apple galls appear to have a curious bimodal pattern of development throughout the summer and fall (Fig. 2, Rosenthal and Koehler 1971b; Schick 2002), it is likely that the first cohort of galls is more often attacked by the inquiline and subsequently inhabited by $B$. nucicola, the parasitoid of the inquiline.

But why do filbert moths emerge so early from their host galls? Filbert moths inhabit oak apple galls and acorns on valley oak as well as other nuts and woody oak galls such as Bebiscus mirabilis on Oregon oak (Dohanian 1942b), and they overwinter as free-living, mature larvae after pushing themselves out of their larval host. The pattern of emergence of filbert moths from oak apple galls suggests that the moths may use the galls as an early season host, and thus maintain an additional generation per year. After emerging from galls in August, they likely oviposit in immature acorns, which are a more abundant resource in August than developing oak apple galls. Interestingly, the parasitoid, Bassus nucicola, has only been reared from filbert moth larvae inside oak apple galls (Dohanian 1942a); this observation suggests that oak apple galls are a common and important host of filbert moths.

What do different attack rates of parasitoids on galls mean for the phenology of the galls? Galls that emerge early in the season accumulate higher abundances of inquilines, which can incur a fitness cost on the gall-inducer by cutting off the plant vasculature that leads to the gall inducer chambers. Conversely, galls that emerge later in the summer are more frequently parasitized by the eulophid parasitoid, B. gigas. Though this study cannot directly assess the selection pressures on the gall-inducer, as we do not know how many gall-inducers were present in the gall prior to parasitoid attack, other studies have found that attack by different predators or parasitoids result in stabilizing selection on aspects of gall morphology such as size (Weis et al. 1992).

Interestingly, most parasitoids and inquilines had both a broader emergence period and a longer diapause time than the gall-inducer (Fig. 2). Many of the parasitoids in this system are known to attack other gall species than A. quercuscalifornicus. Inouye and Agrawal (2004) showed that T. californicus and B. gigas (described as Baryscapus sp.) attack the gall wasp Disholcaspis eldoradensis, which forms stem galls on $Q$. lobata that are sympatric with $A$. quercuscalifornicus and often co-occur on trees. The ability to use multiple 
hosts is consistent with a broad period of emergence of parasitoids, as their phenologies would be expected to be synchronized with their original host if they were monophagous.

The parasite community of oak apple galls consists of many species at different trophic levels, which allows for many complex species interactions (Table 1). Gall size and phenology appear to be important correlates to the abundance of some of the most common insects within those galls. While this study cannot assess whether the difference in host association by parasitoids is caused by niche differentiation (competitive exclusion between different community members under different conditions) or simply reflects innate habitat preferences of the different insects involved, our results are consistent with a pattern of niche differentiation among parasitoids and inquilines of oak apple galls. Manipulations of parasitoid abundances and associations, as well as assessments of parasite host niche-breadths, will ultimately help us to understand the diversity of parasites observed on cynipid galls. Such studies, however, benefit from a detailed examination of the natural histories of the organisms involved, as subtle life history traits can affect the interaction between host and parasite.

Acknowledgments We would like to thank Steve Heydon and John DeBenedictis for help with insect identification, Les Ehler for his help in rearing insects from the galls, and Rick Karban, Les Ehler, and Jay Rosenheim for helpful reviews. This work was supported by an NSF-GRFP grant to ISP.

Open Access This article is distributed under the terms of the Creative Commons Attribution Noncommercial License which permits any noncommercial use, distribution, and reproduction in any medium, provided the original author(s) and source are credited.

\section{References}

Abe Y (2006) Taxonomic status of the genus Trichagalma (Hymenoptera: Cynipidae), with description of the bisexual generation. In: Ozaki K, Yukawa J, Ohgushi T, Price PW (eds) Galling arthropods and their associates: ecology and evolution. Springer, Tokyo, pp 287-295

Askew RR (1980) The diversity of insect communities in leaf mines and plant galls. J Anim Ecol 49(3): $817-829$

Bailey R, Schonrogge K, Cook JM, Melika G, Csoka G, Thuroczy C, Stone GN (2009) Host niches and defensive extended phenotypes structure parasitoid wasp communities. PLoS Biol 7(8):1-12

Craig TP, Itami JK, Price PW (1990) The window of vulnerability of a shoot-galling sawfly to attack by a parasitoid. Ecology 71(4):1471-1482

Csoka G, Stone GN, Melika G (2005) Biology, ecology, and evolution of gall-inducing Cynipidae. In: Raman A, Schaefer CW, Withers TM (eds) Biology, ecology, and evolution of gall-inducing arthropods.2. Science Publishers Enfield, NH, pp 573-642

Dohanian SM (1942a) Parasites of the filbert worm. J Econ Entomol 35(6):836-841

Dohanian SM (1942b) Variability of diapanse in Melissopus latiferreanus. J Econ Entomol 35(3):406-408

Dreger-Jauffret F, Shorthouse JD (1992) Diversity of gall-inducing insects and their galls. In: Shorthouse JD, Rohfrisch O (eds) Biology of insect-induced galls. Oxford University Press, New York

Fernandes GW, Price PW (1992) The adaptive significance of insect gall distribution-survivorship of species in xeric and mesic habitats. Oecologia 90(1):14-20

Fullaway DT (1911) Monograph of the gall-making Cynipidae (Cynipinae) of California. Ann Entomol Soc Am 4(4):331-379

Hayward A, Stone GN (2005) Oak gall wasp communities: evolution and ecology. Basic Appl Ecol 6(5):435-443

Hutchinson GE (1959) Homage to santa-rosalia or why are there so many kinds of animals. Am Nat 93(870): 145-159

Inouye BD, Agrawal AA (2004) Ant mutualists alter the composition and attack rate of the parasitoid community for the gall wasp Disholcaspis eldoradensis (Cynipidae). Ecol Entomol 29:692-696

Jones D (1983) The influence of host density and gall shape on the survivorship of Diastrophus kincaidii Gill (Hymenoptera, Cynipidae). Can J Zool 61(9):2138-2142 
Kinsey AC (1922) Studies of some new and described Cynipidae (Hymernoptera). Indiana University Studies 53:3-171

Liu Z, Engel MS, Grimaldi DA (2007) Phylogeny and geological history of the Cynipoid wasps (Hymenoptera: Cynipoidea). Am Mus Novit (3583):1-48

Marchosky RJ, Craig TP (2004) Gall size-dependent survival for Asphondylia atriplicis (Diptera: Cecidomyiidae) on Atriplex canescens. Environ Entomol 33(3):709-719

Miller DG, Ivey CT, Shedd JD (2009) Support for the microenvironment hypothesis for adaptive value of gall induction in the California gall wasp, Andricus quercuscalifornicus. Entomol Exp Appl 132(2): 126-133

Moorehead JR, Taper ML, Case TJ (1993) Utilization of hybrid oak hosts by a monophagous gall wasphow little host character is sufficient? Oecologia 95(3):385-392

Oksanen J, Blanchet FG, Kindt R, Legendre P, O’Hara B, Simpson G, Solymos P, Stevens MHH, Wagner H (2010) vegan: Community Ecology Package. R package version 1.17.1. http://CRAN.R-project.org/ package $=$ vegan

R Core Development Team (2008) R. The R Foundation

Rohfritsch O (1992) Patterns of gall development. In: Shorthouse JD, Rohfritsch O (eds) Biology of insectinduced galls. Oxford University Press, Oxford

Ronquist F, Liljeblad J (2001) Evolution of the gall wasp-host plant association. Evolution 55(12): 2503-2522

Rosenthal SS, Koehler CS (1971a) Heterogony in some gall-forming Cynipidae (Hymenoptera) with notes on biology of Neuroterus saltatorius. Ann Entomol Soc Am 64(3):565

Rosenthal SS, Koehler CS (1971b) Intertree distributions of some Cynipid (Hymenoptera) galls on Quercus lobata. Ann Entomol Soc Am 64(3):571-574

Russo R (2006) Field guide to plant galls of California and other Western States. University of California Press, Berkeley

Schick KN (2002) Cynipid-induced galls and California oaks. Fremontia 30(3-4):15-18

Schönrogge K, Stone GN, Crawley MJ (1996) Alien herbivores and native parasitoids: rapid developments and structure of the parasitoid and inquiline complex in an invading gall wasp Andricus quercuscalicis (Hymenoptera: Cynipidae). Ecol Entomol 21(1):71-80

Stone GN, Schönrogge K, Crawley MJ, Fraser S (1995) Geographic and between-generation variation in the parasitoid communities associated with an invading gallwasp, Andricus quercuscalicis (Hymenoptera, Cynipidae). Oecologia 104(2):207-217

Stone GN, Schönrogge K, Atkinson RJ, Bellido D, Pujade-Villar J (2002) The population biology of oak gall wasps (Hymenoptera:Cynipidae). Annu Rev Entomol 47:633-668

Stone GN, van der Ham RWJM, Brewer JG (2008) Fossil oak galls preserve ancient multitrophic interactions. Proc Roy Soc B-Biol Sci 275(1648):2213-2219

Stone GN, Hernandez-Lopez A, Nicholls JA, di Pierro E, Pujade-Villar J, Melika G, Cook JM (2009) Extreme host plant conservatism during at least 20 million years of host plant pursuit by oak gall wasps. Evolution 63(4):854-869

Washburn JO (1984) Mutualism between a Cynipid gall wasp and ants. Ecology 65(2):654-656

Weis AE, Kapelinski A (1994) Variable selection on Eurostas gall size 2. A path analysis of the ecological factors behind selection. Evolution 48(3):734-745

Weis AE, Abrahamson WG, Mccrea KD (1985) Host gall size and oviposition success by the parasitoid Eurytoma gigantea. Ecol Entomol 10(3):341-348

Weis AE, Abrahamson WG, Andersen MC (1992) Variable selection on Eurostas gall size 1. The extent and nature of variation in phenotypic selection. Evolution 46(6):1674-1697

Weld LH (1957) Cynipid galls of the Pacific slope. Privately Published Ann Arbor, MI 